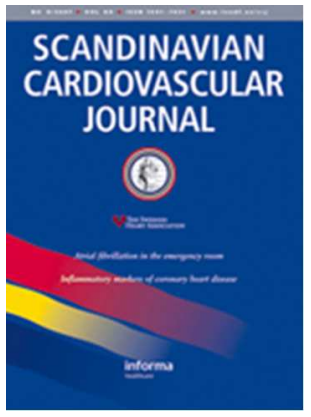

\title{
Effects of Endothelin-1 on intracellular tetrahydrobiopterin levels in vascular tissue
}

\begin{tabular}{|c|c|}
\hline Journal: & Scandinavian Cardiovascular Journal \\
\hline Manuscript ID & SCAR-2017-0282.R2 \\
\hline Manuscript Type: & Original Article \\
\hline Date Submitted by the Author: & $\mathrm{n} / \mathrm{a}$ \\
\hline Complete List of Authors: & $\begin{array}{l}\text { Cerrato, Ruha; Karolinska Institutet, Department of Medicine Solna } \\
\text { Crabtree, Mark; University of Oxford, Department of Cardiovascular } \\
\text { Medicine, John Radcliffe Hospital } \\
\text { Kublickiene, Karolina; Karolinska Institutet, Department of Medicine Solna } \\
\text {; Karolinska Institutet, Institution for Clinical Science, Intervention } \\
\text { \&Technology, Department of Obstetrics \& Gynecology, Karolinska } \\
\text { University Hospital } \\
\text { Antoniades, Charalambos; University of Oxford, Department of } \\
\text { Cardiovascular Medicine, John Radcliffe Hospital } \\
\text { Schiffrin, Ernesto; Lady Davis Institute for Medical Research, Department } \\
\text { of Medicine } \\
\text { Channon, Keith ; University of Oxford, Department of Cardiovascular } \\
\text { Medicine, John Radcliffe Hospital } \\
\text { Böhm, Felix; Karolinska Institutet, Department of Medicine, Cardiology Unit } \\
\text { Karolinska University Hospital }\end{array}$ \\
\hline Keywords: & Endothelin1, intracellular tetrahydrobiopterin, endothelial dysfunction \\
\hline Abstract: & $\begin{array}{l}\text { Tetrahydrobiopterin (BH4) is the essential cofactor of endothelial nitric } \\
\text { oxide synthase (eNOS) and intracellular levels of } \mathrm{BH} 4 \text { is regulated by } \\
\text { oxidative stress. The aim of this paper was to describe the influence of } \\
\text { exogenous endothelin-1 on intracellular } \mathrm{BH} 4 \text { and its oxidation products } \\
\text { dihydrobiopterin (BH2) and biopterin (B) in a wide range of vascular tissue. } \\
\text { Main methods } \\
\text { Segments of internal mammary artery (IMA) and human saphenous vein } \\
(\mathrm{SV}) \text { from } 41 \text { patients undergoing elective surgery were incubated in ET-1 } \\
(0.1 \mu \mathrm{M}) \text {. Aorta and lung from transgenic mice overexpressing ET-1 in the } \\
\text { endothelium (ET-TG) were analysed with regards to intracellular biopterin } \\
\text { levels. Human umbilical vein endothelial cells (HUVEC) were incubated in } \\
\text { ET-1 }(0.1 \mu \mathrm{M}) \text { and intracellular biopterin levels were analysed. From } 6\end{array}$ \\
\hline
\end{tabular}


healthy women undergoing caesarean section, subcutaneous fat was harvested and the resistance arteries in these biopsies were tested for ETmediated endothelial dysfunction.

Key findings

In HUVEC, exogenous ET-1 $(0.1 \mu \mathrm{M})$ did not significantly change intracellular $\mathrm{BH} 4,1.54 \pm 1.7$ vs $1.68 \pm 1.8 \mathrm{pmol} / \mathrm{mg}$ protein; $\mathrm{p}=0.8$. In IMA and SV, exogenous ET-1 $(0.1 \mu \mathrm{M})$ did not change intracellular BH4 $n=10$, $\mathrm{p}=0.4$. In aorta from wild type vs ET-TG mice there was no significant difference in intracellular $\mathrm{BH} 4$ between the groups: $1.3 \pm 0.49$ vs $1.23 \pm 0.3$ $\mathrm{pmol} / \mathrm{mg}$ protein; $\mathrm{p}=0.6$. In resistance arteries $(\mathrm{n}=6) \mathrm{BH} 4$ together with DTE (an antioxidant) was not able to prevent ET-mediated endothelial dysfunction. Conclusion

ET-1 did not significantly alter intracellular tetrahydrobiopterin levels in IMA, SV, HUVEC or aorta from ET-TG mice. These findings are important for future research in ET-1 mediated superoxide production and endothelial dysfunction. 


\title{
Effects of Endothelin-1 on intracellular tetrahydrobiopterin levels in vascular tissue
}

\author{
Ruha Cerrato $^{1}$, Mark Crabtree ${ }^{2}$, Charalambos Antoniades ${ }^{2}$, Karolina Kublickiene ${ }^{3}$, \\ Ernesto Schiffrin ${ }^{4}$, Keith M Channon ${ }^{2}$, Felix Böhm ${ }^{1}$
}

\section{1}

Karolinska Institutet, Department of Medicine, Cardiology unit, Karolinska University Hospital, Stockholm, Sweden, ${ }^{2}$ University of Oxford, Department of Cardiovascular Medicine, John Radcliffe Hospital, Oxford, UK, ${ }^{3}$ Karolinska Institutet, Institution of Medicine and Institution for Clinical Science, Intervention \& Technology, Department of Obstetrics \& Gynecology, Karolinska University Hospital, Sweden, ${ }^{4}$ Lady Davis Institute for Medical Research, Department of Medicine, Sir Mortimer B. Davis-Jewish General Hospital, McGill University, Montreal, Quebec, Canada

Corresponding author: Ruha Cerrato, Department of Cardiology, Karolinska University Hospital, 17176 Stockholm, Sweden

E-mail: ruha.cerrato@sll.se

Tel: 0046-766501254

Fax: 0046-8-311101

Word count: 5288

Figures:3

Tables:2 


\begin{abstract}
Tetrahydrobiopterin (BH4) is the essential cofactor of endothelial nitric oxide synthase (eNOS) and intracellular levels of $\mathrm{BH} 4$ is regulated by oxidative stress. The aim of this paper was to describe the influence of exogenous endothelin-1 on intracellular BH4 and its oxidation products dihydrobiopterin $(\mathrm{BH} 2)$ and biopterin $(\mathrm{B})$ in a wide range of vascular tissue.

Main methods

Segments of internal mammary artery (IMA) and human saphenous vein (SV) from 41 patients undergoing elective surgery were incubated in ET-1 $(0.1 \mu \mathrm{M})$. Aorta and lung from transgenic mice overexpressing ET-1 in the endothelium (ET-TG) were analysed with regards to intracellular biopterin levels. Human umbilical vein endothelial cells (HUVEC) were incubated in ET-1 $(0.1 \mu \mathrm{M})$ and intracellular biopterin levels were analysed. From 6 healthy women undergoing caesarean section, subcutaneous fat was harvested and the resistance arteries in these biopsies were tested for ET-mediated endothelial dysfunction.
\end{abstract}

\title{
Key findings
}

In HUVEC, exogenous ET-1 $(0.1 \mu \mathrm{M})$ did not significantly change intracellular BH4, $1.54 \pm 1.7$ vs $1.68 \pm 1.8 \mathrm{pmol} / \mathrm{mg}$ protein; $\mathrm{p}=0.8$. In IMA and SV, exogenous ET-1(0.1 $\mu \mathrm{M})$ did not change intracellular BH4 $\mathrm{n}=10, \mathrm{p}=0.4$. In aorta from wild type vs ET-TG mice there was no significant difference in intracellular BH4 between the groups: $1.3 \pm 0.49$ vs $1.23 \pm 0.3$ $\mathrm{pmol} / \mathrm{mg}$ protein; $\mathrm{p}=0.6$. In resistance arteries $(\mathrm{n}=6) \mathrm{BH} 4$ together with DTE (an antioxidant) was not able to prevent ET-mediated endothelial dysfunction.

\section{Conclusion}

ET-1 did not significantly alter intracellular tetrahydrobiopterin levels in IMA, SV, HUVEC or aorta from ET-TG mice. These findings are important for future research in ET-1 mediated superoxide production and endothelial dysfunction. 
Cerrato

Keywords: endothelin-1, superoxide, endothelial dysfunction, biopterin, endothelial nitric oxide synthase 


\section{Introduction}

Endothelial dysfunction refers to a condition of reduced bioavailability of NO and increased levels of vasoconstrictors such as endothelin-1. ${ }^{1}$ Endothelin-1 (ET-1) is predominantly produced by vascular endothelial cells, which exerts its effects via two distinctive G-protein coupled receptors: $\mathrm{ET}_{\mathrm{A}}$ and $\mathrm{ET}_{\mathrm{B}}$. The production of $\mathrm{ET}-1$ is increased in the vasculature of patients with atherosclerosis. ${ }^{2}$ We have demonstrated that exogenous ET-1 almost abolishes endothelium-dependent vasodilatation (EDV) in healthy men ${ }^{3}$ and that both selective $\mathrm{ET}_{\mathrm{A}}$ receptor blockade ${ }^{1}$ and dual $\mathrm{ET}_{\mathrm{A}} / \mathrm{ET}_{\mathrm{B}}$ receptor antagonism improves $\mathrm{EDV}$ in patients with atherosclerosis. ${ }^{4}$ These findings imply that ET-1 contributes to reduced NO bioavailability and endothelial dysfunction seen in atherosclerosis. Another important factor in regulating NO bioavailability is the activity of endothelial nitric oxide synthase and one of the major determinants of this enzyme contributing to oxidative stress is the intracellular level of tetrahydrobiopterin $(\mathrm{BH} 4)$ and its oxidation products dihydrobiopterin $(\mathrm{BH} 2)$ and biopterin (B). ${ }^{5}$ We recently demonstrated that ET-1 increases superoxide production in internal mammary artery (IMA) and saphenous vein (SV) from patients with atherosclerosis. ${ }^{13}$ However, the effects of endothelin-1 on intracellular BH4 have not been determined before in vascular tissue from different species. eNOS can, in a state of BH4 deficiency, produce superoxide rather than NO, what is also known as eNOS uncoupling. ${ }^{6}$ Though a range of factors can influence eNOS uncoupling ${ }^{7}$ it would prove futile to investigate such factors if the levels of intracellular BH4 have not been determined. In this paper we aimed to investigate whether ET-1 directly affects tetrahydrobiopterin, but also measure levels of BH2 and B, which are the oxidation products in a set of varying tissues: endothelial cells from mice and humans, tissue from mice overexpressing ET-1 in endothelial cells (ET-TG) as well as in human vessels. We also aimed to show that ET-1 does induce endothelial dysfunction and increase oxidative stress using a model with resistance arteries from healthy women. 


\section{Materials and Methods}

The investigation of ET-1 and its effects on biopterin homeostasis was conducted stepwise, examining levels in sEnd.1 cells (murine endothelial celline), human umbilical vein endothelial cells (HUVEC), aorta and lung from ET-TG mice and IMA and SV. Finally functional effect of superoxide production as determined by endothelium-dependent vasodilatation was studied.

\subsection{Endothelial cells}

sEnd. 1 cells ${ }^{8}$ were investigated first due to their large content of BH4 and a possible ETinduced reduction would therefore be readibly detectable. sEnd.1 cells and HUVEC were grown to sub-confluence and then incubated with or without ET-1 $(0.1 \mathrm{nM}$ to $0.1 \mu \mathrm{M})$ in combination with the dual $\mathrm{ET}_{\mathrm{A}} / \mathrm{ET}_{\mathrm{B}}$ receptor antagonist bosentan $(3 \mu \mathrm{M})$ for various time points. The experiments with HUVEC were repeated five times to ensure validity of the data. The cells were harvested by trypsinization or scraping. Cell pellets were re-suspended in phosphate-buffered saline (50 mM), pH 7.4, containing dithioerythritol (DTE; $1 \mathrm{mM})$ and EDTA $(100 \mu \mathrm{M})$ and subjected to three freeze-thaw cycles. After centrifugation (15 min at 13,000 rpm and $4{ }^{\circ} \mathrm{C}$ ), samples were transferred to new, cooled micro tubes and precipitated with cold phosphoric acid (1 M), trichloroacetic acid (2 M) and DTE (1 mM). Samples were vigorously mixed and then centrifuged for $15 \mathrm{~min}$ at $13,000 \mathrm{rpm}$ and $4{ }^{\circ} \mathrm{C}$. Samples were injected onto an isocratic HPLC system.

\subsection{Tissue from ET-transgenic mice}

Aorta and lung tissue from ET-TG mice was provided by Professor Ernesto Schiffrin, Canada and then sent to the Department of Cardiovascular Medicine, University of Oxford, UK for 
biopterin analyses. For details regarding animal handling we refer to previously published data. ${ }^{9}$ Aorta and lung samples were homogenized in re-suspension buffer (50 $\mathrm{mM}$ phosphate buffered saline, $1 \mathrm{mM}$ DTE, $1 \mathrm{mM}$ EDTA, $\mathrm{pH}$ 7.4) and then followed the same protocol as described for IMA and SV. Dr. Ernesto L Schiffrin, Department of Medicine, Lady Davis Institute, Jewish General Hospital, currently holds an approved Animal Use Protocol \# 20065175 with McGill University and its Affiliated Hospitals' Research Institutes for the following project: Animal Use Protocol Title: Endothelin, vascular inflammation and injury and hypertension / Role of endothelin in elevated blood pressure (hypertension) and vascular injury (injury of arteries).

\subsection{Human vascular tissue}

\section{Study Subjects}

We recruited 41 patients with coronary artery disease undergoing coronary artery bypass grafting at the John Radcliffe Hospital, Oxford, UK. Inclusion criteria were elective and sub acute coronary artery bypass surgery and exclusion criteria were emergency coronary artery bypass surgery and unwillingness to participate. Each patient gave oral and written informed consent to donate plasma and surplus tissue. The study was performed in accordance with the Declaration of Helsinki. Basal characteristics of the patients are presented in Table 1. The study was approved by the local Research Ethics Committee.

\section{Handling the vessel segments}

Samples of internal mammary artery (IMA, n=32), and human saphenous vein $(\mathrm{SV}, \mathrm{n}=22)$ were obtained at the time of coronary artery bypass surgery. The vessel segments were dissected free from surrounding tissue, rinsed from blood and then quickly transported from surgery in ice-cold oxygenated Krebs-HEPES buffer (consisting of [in mmol/1] NaCl 99, $\mathrm{KCl}$ 
4.7, $\mathrm{MgSO}_{4} 1.2, \mathrm{KH}_{2} \mathrm{PO}_{4} 1.0, \mathrm{CaCl}_{2} 1.9, \mathrm{NaHCO}_{3}$ 25, glucose 11.1, Na-HEPES 20) to the laboratory. The segments were then either prepared for superoxide measurement or

determination of biopterin. When determining the effect of ET-1 on endothelial biopterins the vessel segments were prepared as follows: Vascular rings of SV and IMAs were equilibrated in oxygenated $\left(95 \% \mathrm{O}_{2} / 5 \% \mathrm{CO}_{2}\right)$ Krebs-HEPES buffer $(\mathrm{pH} 7.4)$ at $37^{\circ} \mathrm{C}$ with and without ET-1 $\left(10^{-7} \mathrm{M}\right)$ incubation for 45 or $240 \mathrm{~min}$. They were then snap frozen and stored at $-80^{\circ} \mathrm{C}$ until assayed. Vessel rings were subjected to 3 freeze/thaw cycles in re-suspension buffer (50 mM phosphate buffered saline, 1 mM DTE, 1 mM EDTA, pH 7.4), and centrifuged for 15 min at $13,000 \mathrm{rpm}$ and $4^{\circ} \mathrm{C}$. Vascular supernatants were transferred to new, cooled micro tubes and precipitated with cold phosphoric acid $(1 \mathrm{M})$, trichloroacetic acid $(2 \mathrm{M})$ and DTE $(1 \mathrm{mM})$. Samples were vigorously mixed and then centrifuged for $5 \mathrm{~min}$ at 13,000 rpm and $4^{\circ} \mathrm{C}$. Samples were then injected into an isocratic HPLC system.

\section{Determination of tissue biopterin levels with HPLC}

BH4, BH2 and biopterin (B) levels in vessel tissue lysates, ET-TG mice homogenates ${ }^{10}$, cell lysates, and plasma lysates were determined by HPLC followed by electrochemical (for BH4) and fluorescent (for $\mathrm{BH} 2$ and $\mathrm{B}$ ) detection, see below for details. Following homogenization of ET-TG aorta and lung, and when the frozen plasma was thawed DTE (final concentration $1 \mathrm{mM}$ ) was added to prevent oxidation from $\mathrm{BH} 4$ to $\mathrm{BH} 2$. In Table 2 we for the first time report the tissue specific levels of $\mathrm{BH} 4$ and ratio of $\mathrm{BH} 4$ to its oxidation product in endothelial cells, human vascular tissue, mouse aorta and lung tissue.

\section{HPLC conditions}

All HPLC measurements were performed in the Channon lab at the Department of Cardiovascular Medicine, University of Oxford were the method has been extensively 
validated for several years. ${ }^{9}$ Samples were injected onto an isocratic HPLC system and quantified using sequential electrochemical (Coulochem III, ESA Inc., UK) and fluorescence (Jasco, UK) detection. HPLC separation was performed using a $250 \mathrm{~mm}$, ACE C-18 column (Hichrom, UK) and mobile phase comprising $50 \mathrm{mM}$ sodium acetate, $5 \mathrm{mM}$ citric acid, 48 $\mu \mathrm{M}$ EDTA, and $160 \mu \mathrm{M}$ DTE (pH=5.2) (all ultrapure electrochemical HPLC grade) at a flow rate of $1.3 \mathrm{ml} / \mathrm{min}$.

\section{Biopterins detection}

BH4 was measured directly by the electrochemical detector (background currents of $+500 \mathrm{nA}$ and $-50 \mathrm{nA}$ were used for the detection of BH4 on electrochemical cells E1 and E2, respectively). 7,8-BH2 and biopterin were measured as separate chromatographic peeks, in the same sample using a Jasco FP2020 fluorescence detector, serially connected to the electrochemical detector. Quantification of $\mathrm{BH} 4, \mathrm{BH} 2$ and $\mathrm{B}$ was done by comparison with external standards. All samples were loaded in the HPLC auto-sampler in random batches (of up to 12 samples at the time). Each batch was run with an individual standard curve for $\mathrm{BH} 4, \mathrm{BH} 2$ and $\mathrm{B}$. Biopterins levels were expressed as pmol/mg of tissue or protein.

\subsection{Determination of Vascular Superoxide Production}

Vascular superoxide production was measured in paired segments of IMA with the use of lucigenin-enhanced chemiluminescence. ${ }^{11}$ The segments were divided into 4-6 rings, each approx $3 \mathrm{~mm}$ thick, depending on size, weight ranging from 6-20 mg/ring. The vessel segments were opened longitudinally to expose the endothelial surface and equilibrated in oxygenated $\left(95 \% \mathrm{O}_{2} / 5 \% \mathrm{CO}_{2}\right)$ Krebs-HEPES buffer $(\mathrm{pH} 7.4)$ at $37^{\circ} \mathrm{C}$. As a measure of eNOS coupling, we determined NOS-derived superoxide production in paired segments $n=12$, 
which was estimated as the difference in superoxide production after 20 minutes of incubation with the NOS inhibitor $N^{\mathrm{G}}$-nitro-1-arginine methyl ester (L-NAME) alone ${ }^{12}$ or followed by incubation with ET-1 $(0.1 \mathrm{nM})$ for $45 \mathrm{~min}$. The vessel segment was then quickly transferred to a luminometer containing low-concentration lucigenin $(5 \mu \mathrm{mol} / \mathrm{L})$ in order to measure superoxide production.

In a separate set of experiments, additional rings were analyzed after $20 \mathrm{~min}$ preincubation with either the $\mathrm{ET}_{\mathrm{A}}$ receptor antagonist BQ123 $(1 \mu \mathrm{M})$ alone, or in combination with the $\mathrm{ET}_{\mathrm{B}}$ receptor antagonist BQ788 (1 $\mu \mathrm{M}$; dual BQ) followed by ET-1 $(0.1 \mathrm{nM})$ infusion for $45 \mathrm{~min}$. At the end of these experiments, the NADPH-stimulated superoxide production was estimated $10 \mathrm{~min}$ after NADPH $(0.1 \mathrm{mM})$ was added as previously described. ${ }^{12}$

\subsection{Effect of BH4 on ET-induced endothelial dysfunction}

We assessed that ET-1 would induce endothelial dysfunction in resistance arteries in accordance with previous publications. However we had not seen any attempt previously to prevent this dysfunction using exogenous BH4. Hence the experimental design was such that resistance arteries from adipose tissue donated by pregnant women during Caesarian section were exposed to ET-1 and a subset of these vessel segments were pre-incubated with BH4 and BH4 + antioxidant (Dithioerythrothiol; DTE).

In short, segments of resistance arteries were transferred to a 4-channel myograph (Danish Myo Technology, www.dmt.dk $)$, mounted on specimen holders for recording of transversal isometric force; see previous work for details. ${ }^{13}$ Following stabilization and initial baseline tests of acetylcholine-induced endothelium-dependent vasodilation BH4 (1 mM) was added for 20 min together with DTE $1(\mathrm{mM})$ or ascorbic acid $(0.1 \mathrm{mM})$ to prevent oxidation to BH2. After wash out, the vessel segments were pre-contracted with ET-1 (10 nM) or NA (1 
$\mu \mathrm{M}$ followed by a new acetylcholine addition in cumulative steps from $1 \mathrm{nM}$ to 3 or $10 \mu \mathrm{M}$.

These experiments were conducted under the supervision of Dr Karolina Kublickiene at

Karolinska University Hospital and according to the Helsinki Declaration.

\subsection{Substances}

HUVEC were bought from Lonza group Ldt, Switzerland and media supplementation according to Lonzas instructions. sEnd.1 cells were provided by Dr Mark Crabtree ${ }^{5}$, ET-1 (NeoMPS, France) and bosentan (kindly supplied by Dr Martine Clozel, Actelion) was dissolved in Millipore filtered water and stored frozen at $-20^{\circ} \mathrm{C}$. L-NAME (Sigma Aldrich, UK) was dissolved according to manufacturer's instructions and stored frozen at $-20^{\circ} \mathrm{C}$.

\subsection{Statistical Analysis}

Data are expressed as mean \pm SEM if not stated otherwise. Only BH4 levels are shown in the graphs unless a significant change was seen in other biopterin species (dihydrobiopterin and biopterin). All variables were tested for normal distribution with the use of the KolmogorovSmirnov test. Statistical differences were calculated by using Student paired t-test for between group comparisons. All statistical analyses were performed using Graph Pad 4.0 Prism Plus software.

\section{Results}

\subsection{Effect of ET-1 on biopterin levels in endothelial cells}

ET-1 $(0.1 \mu \mathrm{M})$ did not alter biopterin levels in sEnd.1 cells at $24 \mathrm{~h}$, neither did incubation with bosentan alone or co-incubation with ET-1 (data not shown). Since this is an immortalized murine celline we sought to explore whether human endothelial cells would 
give a different response. However, ET-1 $(0.1 \mu \mathrm{M}$ to $0.1 \mathrm{nM})$ did not affect biopterin homeostasis in HUVEC at $24 \mathrm{~h}$ (fig 1A) or $48 \mathrm{~h}$ (fig 1B). Intracellular BH4 remained unchanged after ET-1 exposure $(0.1 \mu \mathrm{M})$ : 18 observations from three separate batches of HUVEC; $1.54 \pm 1.7$ vs $1.68 \pm 1.8 \mathrm{pmol} / \mathrm{mg}$ protein; $\mathrm{p}=0.8$, whereas the ratios of $\mathrm{BH} 4: \mathrm{BH} 2+\mathrm{B}$ were slightly but not significantly increased in comparison to control, $2.25 \pm 3.32 \mathrm{vs}$ $3.07 \pm 4.66 \mathrm{pmol} / \mathrm{mg}$ protein; $\mathrm{p}=0.06$ (data not shown).

\subsection{Biopterin homeostasis in ET-TG mice}

Biopterin levels were not different in aorta and lung tissue (fig 1B shows BH4 levels only) and plasma (data not shown) from ET-TG mice as compared to wild type mice. Intracellular $\mathrm{BH} 4$ and the ratio $\mathrm{BH} 4: \mathrm{BH} 2+\mathrm{B}$ in aorta from ET-TG mice and wild type were also not different $(1.23 \pm 0.3$ vs $1.3 \pm 0.49 \mathrm{pmol} / \mathrm{mg}$ protein; $\mathrm{p}=0.6$ and $1.63 \pm 0.71$ vs $1.38 \pm 0.79 ; \mathrm{p}=0.5$, respectively).

\subsection{Effect of ET- on biopterin levels in IMA and SV}

Incubation of IMA and SV with ET-1(0.1 $\mu \mathrm{M})$ for 45 or $240 \mathrm{~min}$ did not alter biopterin levels nor the ratio of $\mathrm{BH} 4: \mathrm{BH} 2+\mathrm{B}$ in neither IMA nor SV (fig $1 \mathrm{C}$ ): $\mathrm{n}=10 ; \mathrm{p}=0.4$ and $n=12$; $\mathrm{p}=0.8$ respectively. Interestingly there was a significant difference in levels of BH4 in arteries when compared with vein grafts. Earlier we have described a difference in vascular superoxide levels between these vessel grafts. ${ }^{14}$

\section{4 eNOS-derived superoxide production following ET-1 exposure}

To examine a possible role of eNOS-derived superoxide production we performed incubations on a subset of vessel rings with ET-1 +L-NAME and L-NAME alone. In these rings L-NAME inhibitable superoxide fraction was calculated (fig 2A). With this method of 
studying superoxide production ET-1 did not contribute to eNOS-derived superoxide production in IMA, $n=12,0.73 \pm 1.25$ vs ET- $1 ;-0.06 \pm 0.9$ relative light units $(\mathrm{RLU}) / \mathrm{s} / \mathrm{mg}$ tissue; $\mathrm{p}=0.17$, fig $1 \mathrm{C})$. The $\mathrm{ET}_{\mathrm{A}}$ receptor antagonist $\mathrm{BQ} 123$ could markedly inhibit maximal NADPH -stimulated superoxide production in vessel segments (SV) incubated with ET-1 (fig 2 B). Similar significant inhibition of NADPH-stimulated superoxide production could also be achieved by dual $\mathrm{ET}_{\mathrm{A}} / \mathrm{ET}_{\mathrm{B}}$ receptor blockade with $\mathrm{BQ} 123$ and $\mathrm{BQ} 788$ combined in vessel segments incubated with ET-1 as compared to ET-1 alone (only SV, $\mathrm{n}=8, \mathrm{p}=0.04$ ).

\subsection{Effect of BH4 on ET-mediated endothelial dysfunction}

ET-1 induced a marked reduction in endothelium-dependent vasodilation as compared to noradrenaline (NA) in resistance arteries from subcutaneous fat harvested from women undergoing caesarian section (fig 2C). BH4, together with DTE ( $\mathrm{n}=6$ ) was not able to prevent this ET-mediated endothelial dysfunction.

\section{Discussion}

The main findings of the present study are that ET-1 did not evoke any significant change in biopterins in sEnd. 1 cells, HUVEC, ET-TG mice, IMA or SV. Furthermore, BH4 could not inhibit ET-mediated endothelial dysfunction in resistance arteries from healthy pregnant women and L-NAME followed by ET-incubation did not affect ET-mediated superoxide production in IMA. Collectively these observations suggests that the contribution of eNOSderived superoxide production in ET-mediated endothelial dysfunction and superoxide production seems rather small.

We have previously reported that ET-1 almost abolishes endothelium-dependent vasodilatation in healthy men ${ }^{16}$ and induces a marked increase in superoxide production in 
coronary artery bypass grafts ${ }^{14}$ hence it is of importance to further elucidate the mechanistic explanation behind these actions of ET-1. Since it was suggested that ET-1 mediates superoxide production partly through uncoupled eNOS in the rat aorta ${ }^{17}$, we wanted to investigate the link between ET-1 and biopterins in more detail.

Therefore, in the first set of experiments we studied the effect of exogenous ET-1 on biopterins in sEnd. 1 cells, a murine endothelial cell model. This cell line has the advantage of having an abundance of biopterins and high levels of the rate-limiting enzyme guanosine tri phosphate cyclo hydrolase (GTPCH-1) in biopterin synthesis, making it a good model for studying the regulation of $\mathrm{BH} 4$ synthesis and its oxidation in vitro. Our experiments with exogenous ET-1 did not affect BH4 levels substantially or BH2:BH4 ratio in these cells. There are significant differences in biopterin levels between a murine celline and human endothelial cells due to what seems to be the regulation of GTPCH-1. We therefore went on to investigate HUVEC. However, repeated experiments with both time and dose ranging studies showed that exogenous ET-1 did not significantly alter BH4 levels HUVEC either (fig 1A). It has been shown previously that levels of BH4 are quite low in HUVEC, as we could also demonstrate according to Table 2, and one possible explanation has been that GTPCH is shut-off by serum in culture media. ${ }^{18}$ Culture of endothelial cells in serum free media did not lead to an increase in BH4 levels compared to with serum nor any effect of ET1 (data not shown).

We went on to investigate biopterin levels in ET-TG mice. The advantage of using ET-TG mice is that the long-term effects on biopterins of increased local endogenous ET-1 production in endothelial cells could be determined in aorta, lungs as well as plasma. However, even though there is 3-fold higher vascular tissue ET-1 mRNA content and 7-fold higher ET-1 plasma levels in this model ${ }^{10}$, we could not see any effects on biopterins in these 
tissues. It may be due to that this phenotype is relatively healthy without overt

atherosclerosis. In addition, oxidative stress and NADPH oxidase is increased in this model, which together with our findings collectively suggests that ET-1 affects NADPH oxidase rather than eNOS uncoupling in this model.

We therefore went on to study IMA and SV and chose to first incubate the vessel segments for $45 \mathrm{~min}$, a time point where ET-mediated superoxide production was markedly increased. ${ }^{14}$ However, neither 45 min nor 240 min incubation with ET-1 resulted in any changes in biopterins in neither IMA nor SV (fig 1C). These novel findings in vascular tissue from patients with coronary artery disease suggest that BH4 deficiency and eNOS uncoupling is of little importance in ET-mediated superoxide production in humans.

Increased superoxide production is a key factor in disease progression and ET-1 contributes to this process particularly in cardiovascular disease states such as coronary artery disease. ${ }^{19}$ We reported recently that ET-1 could increase superoxide production, most likely via NADPH oxidase in human coronary artery bypass grafts. ${ }^{14}$ It would be possible that this increase in superoxide production would lead to oxidation of $\mathrm{BH} 4$ and result in eNOS uncoupling alternatively ET-1 could have direct effects on biopterins. In the present study, we found no L-NAME inhibitable fraction of ET-induced superoxide production suggesting that the superoxide produced originated through other sources (fig 2A). In fact, the finding that maximal NADPH stimulated superoxide production was markedly reduced during ET receptor blockade indicates that a major source is NADPH oxidase (fig 2B). Zheng et al describes a low renin hypertension model in rat, where exogenous ET-1 increases superoxide production in carotid arteries. Also in this model L-NAME does not inhibit ET-induced superoxide production. Only apocynin and ET receptor antagonism can inhibit this increase, indicating that the main source of superoxide induced by ET-1 is NADPH oxidase ${ }^{20}$ in line with both findings in the present study and our recent findings in human vascular tissue. ${ }^{14}$ 
Finally we wanted to investigate whether ET-1 induced endothelial dysfunction could be inhibited by exogenous BH4. We performed a set of experiments on resistance arteries from subcutaneous fat harvested from women undergoing caesarian section. However, BH4 was not able to inhibit the marked ET-mediated endothelial dysfunction in these resistance arteries (fig $2 \mathrm{C}$ ). This observation goes in line with Romero et al, who report ET-induced endothelial dysfunction in rat aorta following $2 \mathrm{~h}$ incubation with ET-1 which could not be restored with the BH4 precursor sepiapterin ${ }^{21}$. In conflict with our present results, the same study showed that L-NAME inhibitable superoxide production was evident following $2 \mathrm{~h}$ ET-1 incubation in the presence of the calcium ionophore A23187. The use of this calcium ionophore and that the incubation time with ET-1 was 75 min longer are two factors that may explain the differences in our studies. Also Loomis et al reported that ETmediated superoxide production could be inhibited by not only L-NAME, but also by BH4, in the rat aorta. ${ }^{17}$ Differences to our study are that pre incubation was 60 min with L-NAME or BH4, and ET-1 incubation followed thereafter for $240 \mathrm{~min}$. Importantly, there may also be species differences and we have in the present study shown that 45 or 240 min ET-1 exposure does not affect biopterins and that there is no L-NAME inhibitable superoxide production in ET-exposed vessels from patients with coronary artery disease.

\subsection{Limitations}

First; the study cohort consisted of patients with ongoing medication with betablockers, angiotensin receptor blockers, statins and nitrates. These can all affect superoxide production. However, endothelial dysfunction and effect of ET-1 would have been even more pronounced if the patients were not medicated. A very large percentage of the study population was treated with statins. Statins have a pleiotropic effect on endothelial function in patients with cardiovascular disease, and it has been described to promote antioxidant 
effects in the vessel wall. ${ }^{22}$ In a study conducted on patients with moderate to very high atherosclerotic cardiovascular disease the use of statins was shown to increase plasma levels of superoxide dismutase and reduce nitrite formation indicating a reduced level of oxidative stress. $^{23}$ Second, the experiments were performed in vessels ex vivo, handling and homogenization in order to measure biopterins can possibly contribute and it is still unclear whether ET-1 could possibly have an effect on biopterin homeostasis in vivo. However, longterm endogenous ET-1 did not affect biopterins in ET-TG mice. Third, the concentration of exogenous ET-1 in the superoxide measurements was significantly lower than in the vessel incubations for biopterin measurements. Since no effect on biopterin was seen in HUVEC at concentrations of $0.1 \mu \mathrm{m}-0.1 \mathrm{~nm}$ we argue that it is unlikely that a lower concentration of ET-1 could have changed the outcome in vessel biopterin levels. Fourth, we did not study eNOS monomer: dimer ratio, which has been suggested as a possible indicator of eNOS uncoupling. However, separate to our studies the group of Vasques-Vivar have elegantly shown that eNOS coupling is not determined by monomer-dimer ratio but rather $\mathrm{BH} 4: \mathrm{BH} 2+\mathrm{B}$ ratio ${ }^{24}$ hence we did not find it necessary to study a parameter which will not give us more information into the question of eNOS coupling than measuring intracellular levels of biopterins.

\section{Conclusions}

ET-1 did not evoke any significant change in biopterins in sEnd.1 cells, HUVEC, ET-TG mice or coronary artery bypass grafts. Furthermore, BH4 could not inhibit ET-mediated endothelial dysfunction in resistance arteries from pregnant women and L-NAME pre incubation followed by ET-incubation did not affect ET-mediated superoxide production in IMA and SV. Together with the observation that NADPH -stimulated superoxide production was markedly reduced during ET receptor blockade collectively these findings suggest that 
ET-1 plays a minor role in the contribution to eNOS uncoupling in these tissues. It rather indicates that a major source of ET-induced superoxide production is NADPH oxidase in the human vasculature. We could not find any biologically or statistically significant effect of ET-1 on intracellular tetrahydrobiopterin and our main hypothesis was consequently not met. We therefore conclude that the present data suggests that ET-1 plays a minor role in the contribution to eNOS uncoupling in human vasculature.

\section{Funding}

This study was funded by the Swedish Heart-Lung foundation, the Swedish Medical Research Council, the Stockholm County Council (ALF) and the National Institute for Health Research (NIHR) Oxford Biomedical Research Centre - grants for KM Channon.

\section{Acknowledgements}

We gratefully acknowledge the skilled help in harvesting vessels from the cardiothoracic surgeons Ravi Sayeed, Chandi Ratnatunga, Ravi Pillai and David Taggart at John Radcliffe Hospital, Oxford, UK.

\section{Conflict of interests}

None to report. 
Table 1. Individual characteristics of patients undergoing coronary artery bypass surgery

\begin{tabular}{ll}
\hline No of patients & 41 \\
Men/women & $36 / 5$ \\
Age (y, mean \pm SD) & $68 \pm 8$ \\
& \\
Risk factors, n (\%) & \\
Hypertension & $26(63)$ \\
Hypercholesterolemia & $31(76)$ \\
Smokers/exsmokers & $5 / 27$ \\
Diabetes mellitus & $11(27)$ \\
$\quad$ Type II & $9(81)$ \\
Family history & $20(49)$ \\
Body mass index, kg/m ${ }^{2}$ & $29 \pm 6$ \\
& \\
Medication, $n(\%)$ & \\
Statins & \\
Angiotensin-converting enzyme inhibitors & $39(95)$ \\
Angiotensin receptor blockers & $22(54)$ \\
Beta blockers & $11(27)$ \\
Nitrates & $35(85)$ \\
Aspirin & $20(49)$ \\
\hline Valus are expressed as mean $(\%)$ & $21(51)$ \\
\hline
\end{tabular}

Values are expressed as mean (\%) 
Table 2. Tissue specific levels of $\mathrm{BH} 4$ and $\mathrm{BH} 4 / \mathrm{BH} 2+\mathrm{B}$ ratios $(\mathrm{pmol} / \mathrm{mg}$ protein if not stated otherwise)

\begin{tabular}{|l|l|l|l|l|l|}
\hline Tissue & $\mathrm{N}$ & $\begin{array}{l}\text { Control } \\
\text { BH4 } \\
\text { Mean } \pm \text { SD }\end{array}$ & $\begin{array}{l}\text { BH4/BH2+B } \\
\text { Mean } \pm \text { SD }\end{array}$ & $\begin{array}{l}\text { ET-1 } \\
\text { BH4 } \\
\text { Mean } \pm \text { SD }\end{array}$ & $\begin{array}{l}\text { BH4/BH2+B } \\
\text { Mean } \pm \text { SD }\end{array}$ \\
\hline $\begin{array}{l}\text { IMA } \\
(45 m i n)\end{array}$ & 10 & $18.0 \pm 13$ & $1.3 \pm 0.9$ & $14.4 \pm 12.1$ & $0.9 \pm 0.7$ \\
\hline $\begin{array}{l}\text { SV (45 } \\
\text { min) }\end{array}$ & 12 & $5.3 \pm 3.5$ & $1.0 \pm 0.6$ & $5.3 \pm 3.4$ & $0.9 \pm 07$ \\
\hline HUVEC & $3^{2}$ & $1.54 \pm 1.67$ & $2.3 \pm 3.3$ & $1.68 \pm 1.87$ & $3.1 \pm 4.7$ \\
\hline $\begin{array}{l}\text { Aorta } \\
\text { (Wt) }\end{array}$ & 18 & $1.3 \pm 0.5$ & $1.4 \pm 0.8$ & $1.23 \pm 0.3$ & $1.6 \pm 0.7$ \\
\hline $\begin{array}{l}\text { Aorta } \\
\text { (ET-TG) }\end{array}$ & 22 & & & & \\
\hline $\begin{array}{l}\text { Lung } \\
\text { (Wt) }\end{array}$ & 18 & $2.15 \pm 0.9$ & $0.4 \pm 0.2$ & $2.5 \pm 1.5$ & $0.4 \pm 0.2$ \\
\hline $\begin{array}{l}\text { Lung } \\
\text { (ET-TG) }\end{array}$ & 22 & & & & \\
\hline
\end{tabular}

${ }^{1} \mathrm{pmol} / \mathrm{mg}$ tissue

${ }^{2}$ Three separate experiments, different HUVEC batches, total of 18 observations per intervention

${ }^{3} \mathrm{BH} 4$ mean between wt and ET-TG

\section{References}

1. Böhm F, Ahlborg G, Johansson BL, et al. Combined endothelin receptor blockade evokes enhanced vasodilatation in patients with atherosclerosis. Arterioscler Thromb Vasc Biol 2002;22(4):674-9.

2. Lerman A, Edwards BS, Hallett JW, et al. Circulating and tissue endothelin immunoreactivity in advanced atherosclerosis. N Engl J Med 1991;325(14):997-1001. doi: 10.1056/NEJM199110033251404 [published Online First: 1991/10/13]

3. Böhm F, Pernow J. The importance of endothelin-1 for vascular dysfunction in cardiovascular disease. Cardiovasc Res 2007;76(1):8-18. doi: 10.1016/j.cardiores.2007.06.004

4. Böhm F, Beltran E, Pernow J. Endothelin receptor blockade improves endothelial function in atherosclerotic patients on angiotensin converting enzyme inhibition. $J$ Intern Med 2005;257:263-71.

5. Crabtree MJ, Tatham AL, Al-Wakeel Y, et al. Quantitative regulation of intracellular endothelial nitric-oxide synthase (eNOS) coupling by both tetrahydrobiopterin-eNOS stoichiometry and biopterin redox status: insights from cells with tet-regulated GTP 
cyclohydrolase I expression. J Biol Chem 2009;284(2):1136-44. doi:

10.1074/jbc.M805403200

6. Bendall JK, Alp NJ, Warrick N, et al. Stoichiometric relationships between endothelial tetrahydrobiopterin, endothelial NO synthase (eNOS) activity, and eNOS coupling in vivo: insights from transgenic mice with endothelial-targeted GTP cyclohydrolase 1 and eNOS overexpression. Circ Res 2005;97(9):864-71. doi: 01.RES.0000187447.03525.72 [pii] 10.1161/01.RES.0000187447.03525.72 [published Online First: 2005/09/24]

7. Bendall JK, Douglas G, McNeill E, et al. Tetrahydrobiopterin in cardiovascular health and disease. Antioxid Redox Signal 2014;20(18):3040-77. doi: 10.1089/ars.2013.5566

8. Williams RL, Risau W, Zerwes HG, et al. Endothelioma cells expressing the polyoma middle T oncogene induce hemangiomas by host cell recruitment. Cell 1989;57(6):1053-63.

9. Crabtree MJ, Channon KM. Synthesis and recycling of tetrahydrobiopterin in endothelial function and vascular disease. Nitric Oxide 2011;25(2):81-8. doi: S10898603(11)00392-2 [pii] 10.1016/j.niox.2011.04.004 [published Online First: 2011/05/10]

10. Amiri F, Virdis A, Neves MF, et al. Endothelium-restricted overexpression of human endothelin-1 causes vascular remodeling and endothelial dysfunction. Circulation 2004;110(15):2233-40. doi: 10.1161/01.CIR.0000144462.08345.B9

11. Guzik TJ, Channon KM. Measurement of vascular reactive oxygen species production by chemiluminescence. Methods Mol Med 2005;108:73-89. [published Online First: 2005/07/21]

12. Antoniades C, Shirodaria C, Leeson P, et al. MTHFR $677 \mathrm{C}>\mathrm{T}$ Polymorphism reveals functional importance for 5-methyltetrahydrofolate, not homocysteine, in regulation of vascular redox state and endothelial function in human atherosclerosis. Circulation 2009;119(18):2507-15. doi: CIRCULATIONAHA.108.808675 [pii] 10.1161/CIRCULATIONAHA.108.808675 [published Online First: 2009/04/29]

13. Luksha L, Stenvinkel P, Hammarqvist F, et al. Mechanisms of endothelial dysfunction in resistance arteries from patients with end-stage renal disease. PLoS One 2012;7(4):e36056. doi: 10.1371/journal.pone.0036056

14. Cerrato R, Cunnington C, Crabtree MJ, et al. Endothelin-1 increases superoxide production in human coronary artery bypass grafts. Life Sci 2012;91(13-14):723-8. doi: S0024-3205(12)00147-6 [pii] 10.1016/j.lfs.2012.03.024 [published Online First: 2012/04/10]

15. Zeiher AM, Ihling C, Pistorius K, et al. Increased tissue endothelin immunoreactivity in atherosclerotic lesions associated with acute coronary syndromes. Lancet 1994;344(8934):1405-6. doi: S0140-6736(94)90571-1 [pii] [published Online First: 1994/11/19]

16. Böhm F, Ahlborg G, Pernow J. Endothelin-1 inhibits endothelium-dependent vasodilatation in the human forearm: reversal by ETA receptor blockade in patients with atherosclerosis. Clinical science 2002;102(3):321-7.

17. Loomis ED, Sullivan JC, Osmond DA, et al. Endothelin mediates superoxide production and vasoconstriction through activation of NADPH oxidase and uncoupled nitricoxide synthase in the rat aorta. J Pharmacol Exp Ther 2005;315(3):1058-64. doi: 10.1124/jpet.105.091728

18. Rosenkranz-Weiss P, Sessa WC, Milstien S, et al. Regulation of nitric oxide synthesis by proinflammatory cytokines in human umbilical vein endothelial cells. Elevations in tetrahydrobiopterin levels enhance endothelial nitric oxide synthase specific activity. 
J Clin Invest 1994;93(5):2236-43. doi: 10.1172/JCI117221 [published Online First: 1994/05/01]

19. Barton M, d'Uscio LV, Shaw S, et al. ET(A) receptor blockade prevents increased tissue endothelin-1, vascular hypertrophy, and endothelial dysfunction in salt-sensitive hypertension. Hypertension 1998;31(1 Pt 2):499-504. [published Online First: 1998/02/07]

20. Zheng JS, Yang XQ, Lookingland KJ, et al. Gene transfer of human guanosine 5'triphosphate cyclohydrolase I restores vascular tetrahydrobiopterin level and endothelial function in low renin hypertension. Circulation 2003;108(10):1238-45. doi: 10.1161/01.CIR.0000089082.40285.C3

21. Romero M, Jimenez R, Sanchez M, et al. Quercetin inhibits vascular superoxide production induced by endothelin-1: Role of NADPH oxidase, uncoupled eNOS and PKC. Atherosclerosis 2009;202(1):58-67. doi: 10.1016/j.atherosclerosis.2008.03.007

22. Oesterle A, Laufs U, Liao JK. Pleiotropic Effects of Statins on the Cardiovascular System. Circ Res 2017;120(1):229-43. doi: 10.1161/CIRCRESAHA.116.308537 [published Online First: 2017/01/07]

23. Mayyas F, Baydoun D, Ibdah R, et al. Atorvastatin Reduces Plasma Inflammatory and Oxidant Biomarkers in Patients With Risk of Atherosclerotic Cardiovascular Disease. J Cardiovasc Pharmacol Ther 2018:1074248417753677. doi: 10.1177/1074248417753677 [published Online First: 2018/01/19]

24. Whitsett J, Martasek P, Zhao H, et al. Endothelial cell superoxide anion radical generation is not dependent on endothelial nitric oxide synthase-serine 1179 phosphorylation and endothelial nitric oxide synthase dimer/monomer distribution. Free Radic Biol Med 2006;40(11):2056-68. doi: 10.1016/j.freeradbiomed.2006.02.001 
Figure legends

(Figures are uploaded separately as TIFF and 1200 DPI)

Fig 1 .A. Quantification of BH4 in HUVEC incubated with ET-1 in a doseranging study. $(\mathrm{n}=3)$. B. In ET-TG mice there was no significant difference in vascular tetrahydrobiopterin (BH4) Aortas ET_TG vs WT, $n=22, p=0.6)$ nor in pulmonary tissue $(n=18, p=0.4)$. C. Vascular BH4 in SV ( $\mathrm{n}=12$ for $45 \mathrm{~min}$ and $\mathrm{n}=6$ for $240 \mathrm{~min})$ and IMA ( $\mathrm{n}=10$ for $45 \mathrm{~min}$ and $\mathrm{n}=9$ for $240 \mathrm{~min})$ in the presence and absence of ET-1 $(0.1 \mathrm{uM})$. Values are mean \pm SEM, $* * \mathrm{p}<0.001$ refers to IMA vs SV

Fig. 2 A. L-NAME inhibitable fraction of vascular superoxide in IMA incubated with ET-1 for $45 \min (n=12$, ns) determined by lucigenin-enhanced chemiluminescence. B. NADPH oxidase activity in SV in the presence and absence of ET-1 and ETA receptor blocker BQ123 $\left(\mathrm{n}=8,{ }^{*} \mathrm{p}<0.05\right.$ control vs ET-1 + BQ123, and \# $<<0.05$ : BQ123+ET-1 vs BQ123 alone). C. ET-1 in resistance arteries with significant reduction of relaxation to $\mathrm{ACH}(n=6, p<0.05)$ in comparison to Norepinephrine (NE, $n=6)$. Endothelial function in these vessels was not restored with ET-1+tetrahydrobiopterin in combination with tetrahydrobiopterin $(n=6)$. All values are mean \pm SEM. ${ }^{*}<<0.05$. 


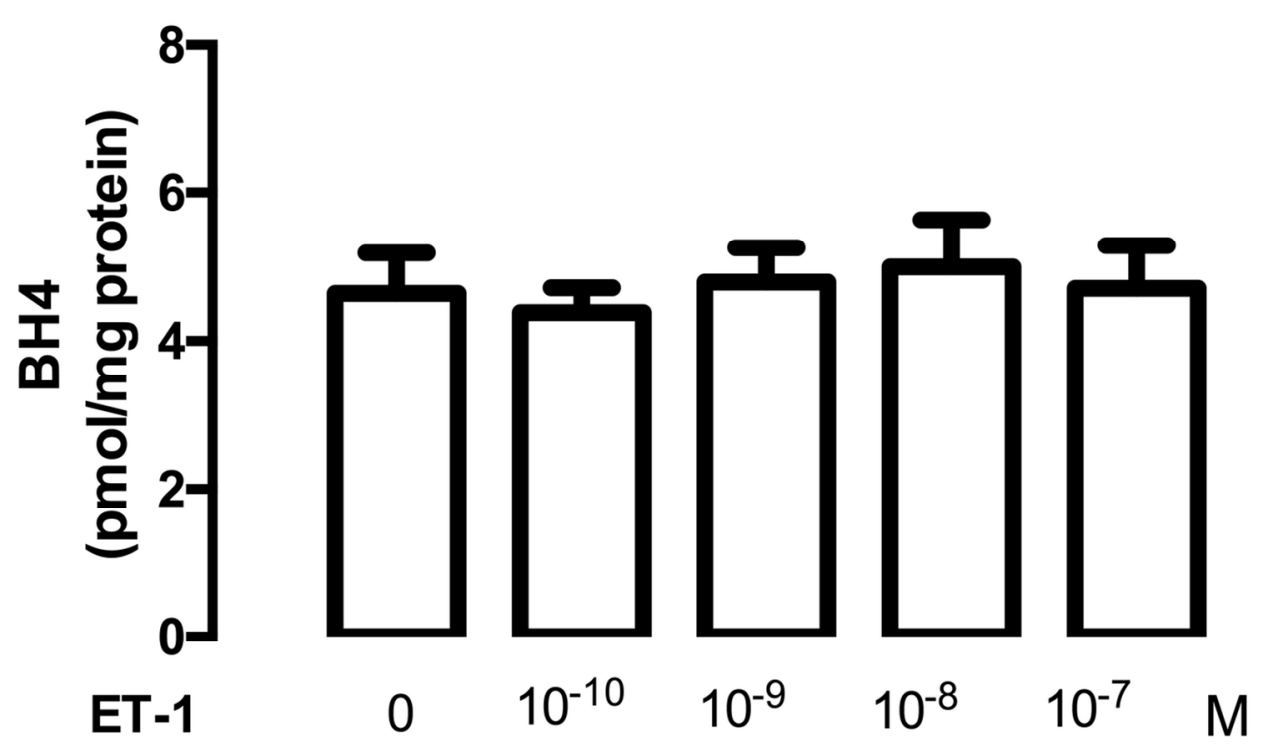

A. Quantification of BH4 in HUVEC incubated with ET-1 in a doseranging study. $(n=3)$. $121 \times 74 \mathrm{~mm}(300 \times 300 \mathrm{DPI})$ 


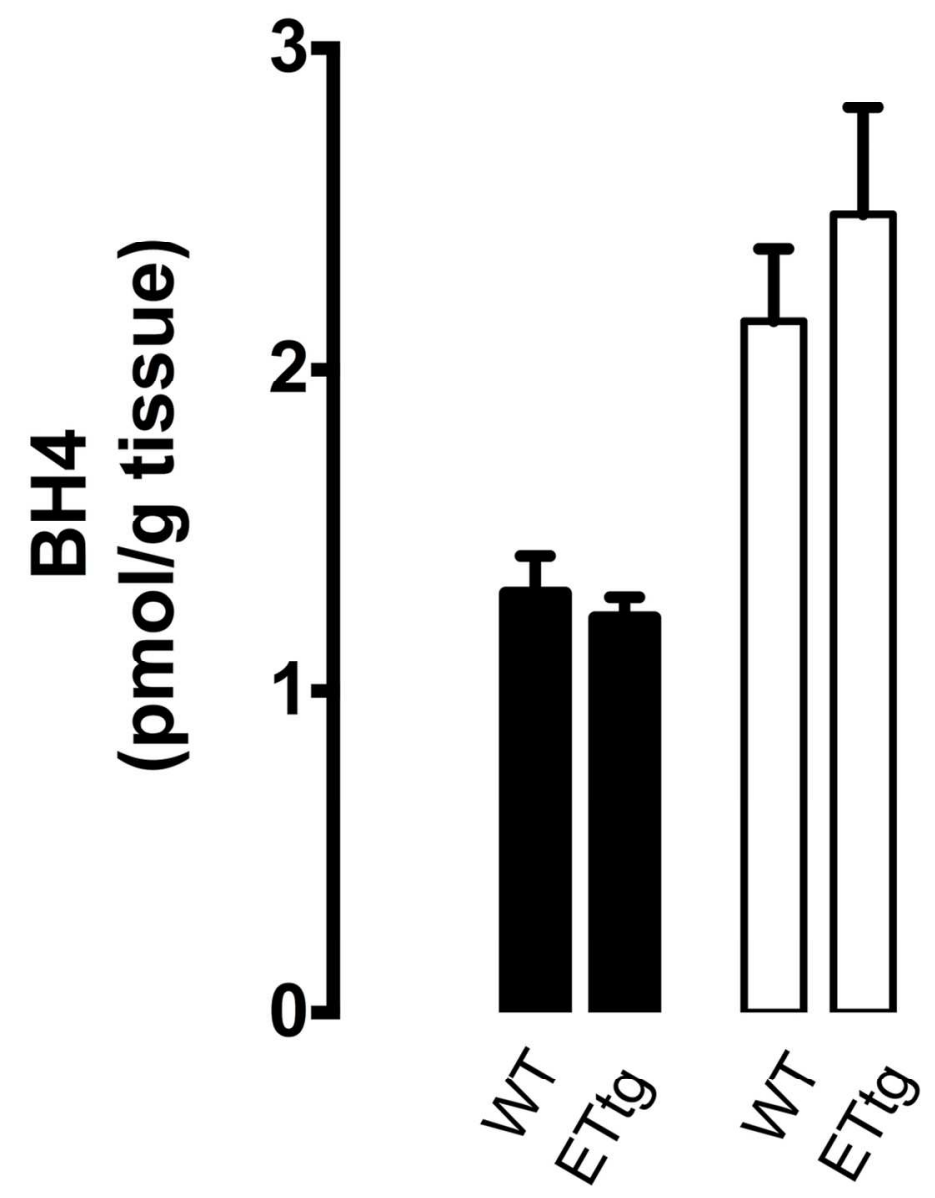

B. In ET-TG mice there was no significant difference in vascular tetrahydrobiopterin (BH4) Aortas ET_TG vs WT, $n=22, p=0.6)$ nor in pulmonary tissue $(n=18, p=0.4)$.

$122 \times 118 \mathrm{~mm}(300 \times 300 \mathrm{DPI})$ 


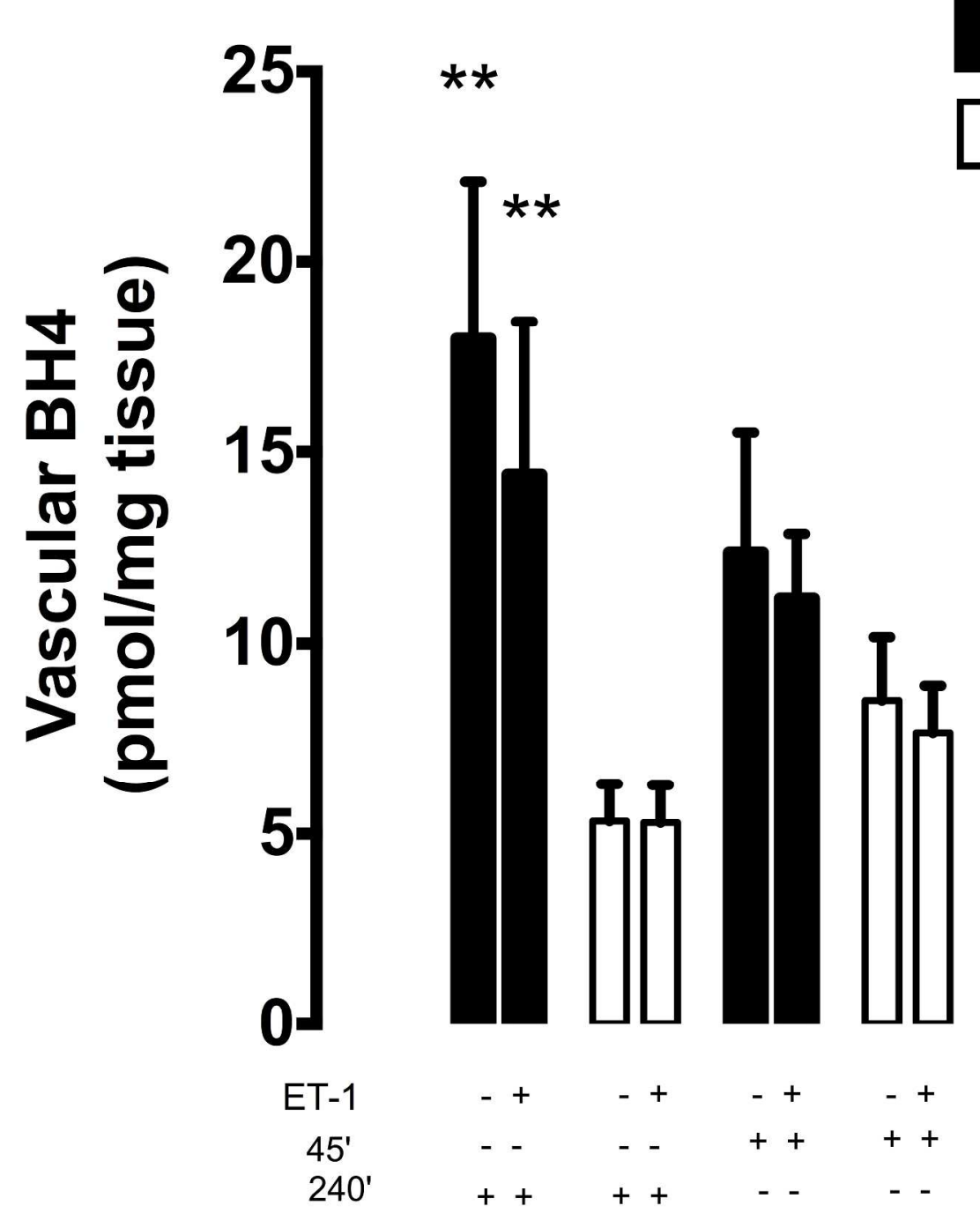

C. Vascular BH4 in SV ( $n=12$ for 45 min and $n=6$ for $240 \min$ ) and IMA ( $n=10$ for 45 min and $n=9$ for $240 \mathrm{~min})$ in the presence and absence of ET-1 (0.1uM). Values are mean \pm SEM, $* * p<0.001$ refers to IMA vs SV

$276 \times 300 \mathrm{~mm}(300 \times 300 \mathrm{DPI})$ 


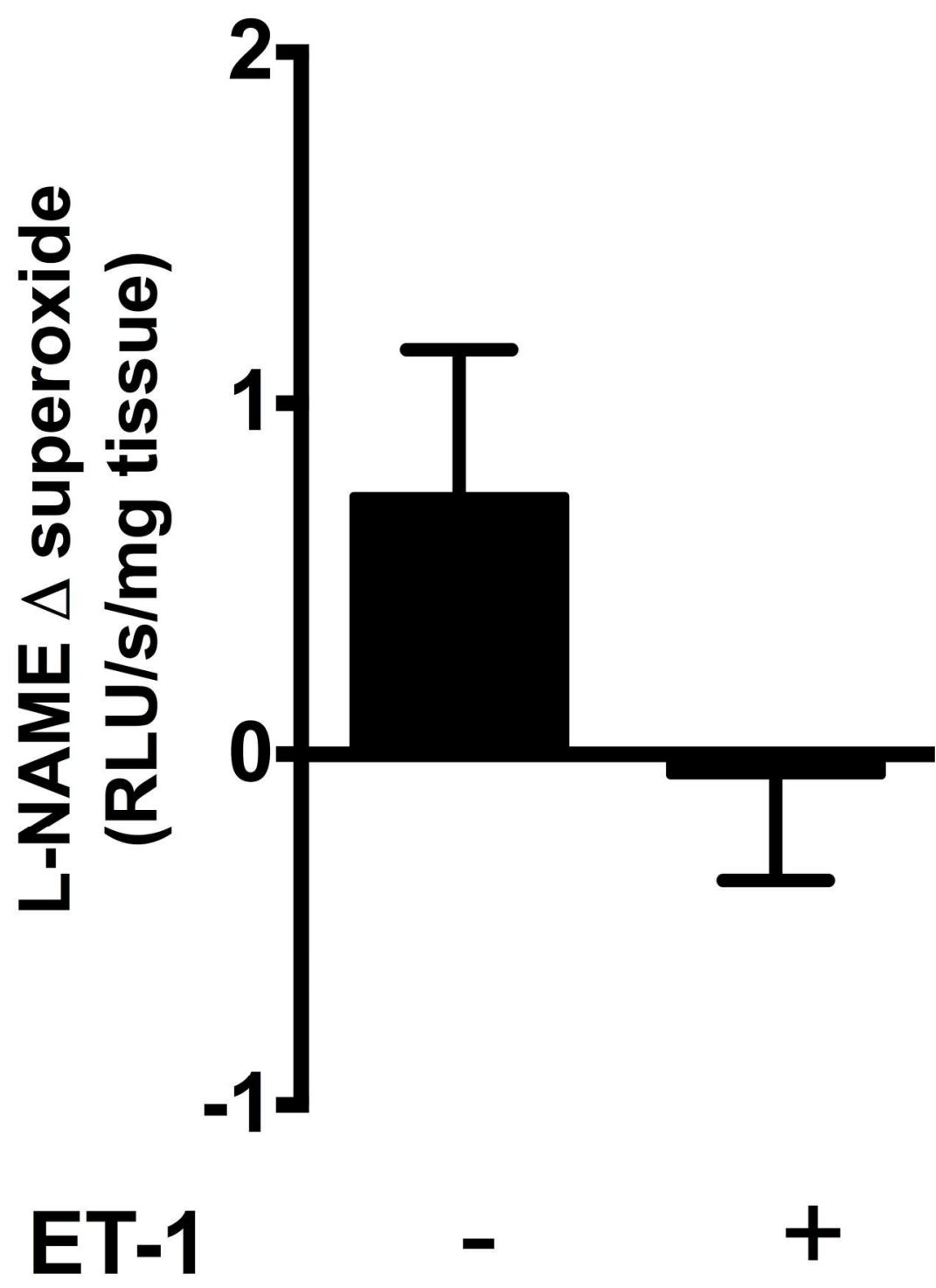

A. L-NAME inhibitable fraction of vascular superoxide in IMA incubated with ET-1 for $45 \mathrm{~min}(\mathrm{n}=12, \mathrm{~ns})$ determined by lucigenin-enhanced chemiluminescence.

$183 \times 237 \mathrm{~mm}(300 \times 300 \mathrm{DPI})$ 


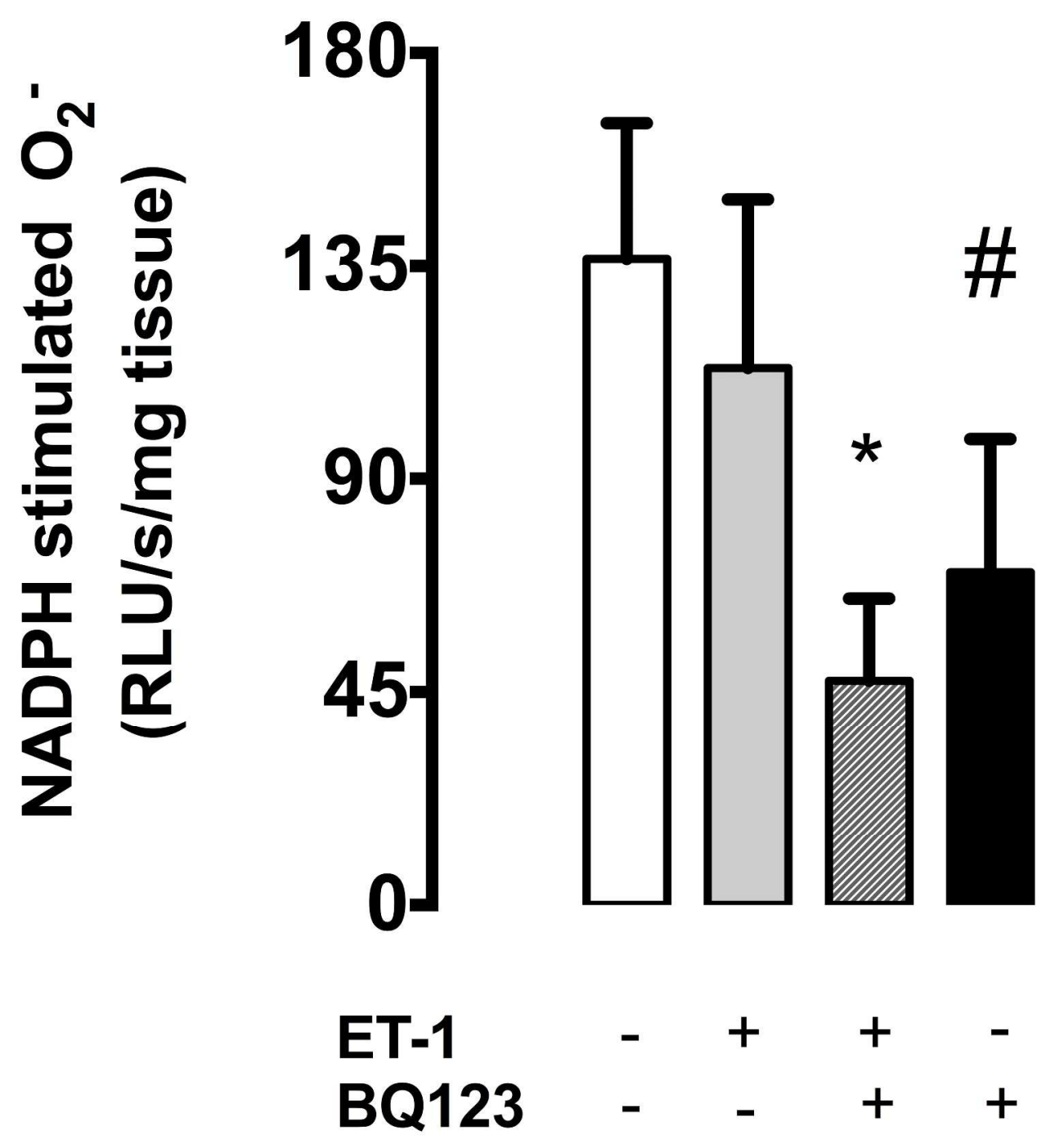

B. NADPH oxidase activity in SV in the presence and absence of ET-1 and ETA receptor blocker BQ123 ( $n=8$, ${ }^{*} \mathrm{p}<0.05$ control vs ET-1 + BQ123, and \# p<0.05: BQ123+ET-1 vs BQ123 alone).

$285 \times 321 \mathrm{~mm}(300 \times 300 \mathrm{DPI})$ 
C. ET-1 in resistance arteries with significant reduction of relaxation to $\mathrm{ACH}(\mathrm{n}=6, \mathrm{p}<0.05)$ in comparison to Norepinephrine $(N E, n=6)$. Endothelial function in these vessels was not restored with $E T-$ $1+$ tetrahydrobiopterin in combination with tetrahydrobiopterin $(n=6)$. All values are mean \pm SEM. $* p<0.05$. $236 \times 220 \mathrm{~mm}(300 \times 300 \mathrm{DPI})$ 
Supplementary document

\section{Author information}

Ruha Cerrato $^{1}$, Mark Crabtree ${ }^{2}$, Charalambos Antoniades ${ }^{2}$, Karolina Kublickiene $^{3}$, Ernesto Schiffrin $^{4}$, Keith M Channon ${ }^{2}$, Felix Böhm ${ }^{1}$

${ }^{1}$ Karolinska Institutet, Department of Medicine, Cardiology unit, Karolinska University Hospital, Stockholm, Sweden, ${ }^{2}$ University of Oxford, Department of Cardiovascular Medicine, John Radcliffe Hospital, Oxford, UK, ${ }^{3}$ Karolinska Institutet, Institution of Medicine and Institution for Clinical Science, Intervention \& Technology, Department of Obstetrics \& Gynecology, Karolinska University Hospital, Sweden, ${ }^{4}$ Lady Davis Institute for Medical Research, Department of Medicine, Sir Mortimer B. Davis-Jewish General Hospital, McGill University, Montreal, Quebec, Canada

Corresponding author: Ruha Cerrato, Department of Cardiology, Karolinska University Hospital, 17176 Stockholm, Sweden

E-mail: ruha.cerrato@sll.se

Tel: 0046-766501254

Fax: 0046-8-311101 
1. Böhm F, Ahlborg G, Johansson BL, et al. Combined endothelin receptor blockade evokes enhanced vasodilatation in patients with atherosclerosis. Arterioscler Thromb Vasc Biol 2002;22(4):674-9.

2. Lerman A, Edwards BS, Hallett JW, et al. Circulating and tissue endothelin immunoreactivity in advanced atherosclerosis. N Engl J Med 1991;325(14):997-1001. doi: 10.1056/NEJM199110033251404 [published Online First: 1991/10/13]

3. Böhm F, Pernow J. The importance of endothelin-1 for vascular dysfunction in cardiovascular disease. Cardiovasc Res 2007;76(1):8-18. doi: 10.1016/j.cardiores.2007.06.004

4. Böhm F, Beltran E, Pernow J. Endothelin receptor blockade improves endothelial function in atherosclerotic patients on angiotensin converting enzyme inhibition. $J$ Intern Med 2005;257:263-71.

5. Crabtree MJ, Tatham AL, Al-Wakeel Y, et al. Quantitative regulation of intracellular endothelial nitric-oxide synthase (eNOS) coupling by both tetrahydrobiopterin-eNOS stoichiometry and biopterin redox status: insights from cells with tet-regulated GTP cyclohydrolase I expression. J Biol Chem 2009;284(2):1136-44. doi: 10.1074/jbc.M805403200

6. Bendall JK, Alp NJ, Warrick N, et al. Stoichiometric relationships between endothelial tetrahydrobiopterin, endothelial NO synthase (eNOS) activity, and eNOS coupling in vivo: insights from transgenic mice with endothelial-targeted GTP cyclohydrolase 1 and eNOS overexpression. Circ Res 2005;97(9):864-71. doi: 01.RES.0000187447.03525.72 [pii] 10.1161/01.RES.0000187447.03525.72 [published Online First: 2005/09/24]

7. Bendall JK, Douglas G, McNeill E, et al. Tetrahydrobiopterin in cardiovascular health and disease. Antioxid Redox Signal 2014;20(18):3040-77. doi: 10.1089/ars.2013.5566

8. Williams RL, Risau W, Zerwes HG, et al. Endothelioma cells expressing the polyoma middle $\mathrm{T}$ oncogene induce hemangiomas by host cell recruitment. Cell 1989;57(6):1053-63.

9. Crabtree MJ, Channon KM. Synthesis and recycling of tetrahydrobiopterin in endothelial function and vascular disease. Nitric Oxide 2011;25(2):81-8. doi: S10898603(11)00392-2 [pii] 10.1016/j.niox.2011.04.004 [published Online First: 2011/05/10]

10. Amiri F, Virdis A, Neves MF, et al. Endothelium-restricted overexpression of human endothelin-1 causes vascular remodeling and endothelial dysfunction. Circulation 2004;110(15):2233-40. doi: 10.1161/01.CIR.0000144462.08345.B9

11. Guzik TJ, Channon KM. Measurement of vascular reactive oxygen species production by chemiluminescence. Methods Mol Med 2005;108:73-89. [published Online First: 2005/07/21]

12. Antoniades C, Shirodaria C, Leeson P, et al. MTHFR 677 C $>$ T Polymorphism reveals functional importance for 5-methyltetrahydrofolate, not homocysteine, in regulation of vascular redox state and endothelial function in human atherosclerosis. Circulation 2009;119(18):2507-15. doi: CIRCULATIONAHA.108.808675 [pii] 10.1161/CIRCULATIONAHA.108.808675 [published Online First: 2009/04/29]

13. Luksha L, Stenvinkel P, Hammarqvist F, et al. Mechanisms of endothelial dysfunction in resistance arteries from patients with end-stage renal disease. PLoS One 2012;7(4):e36056. doi: 10.1371/journal.pone.0036056 
14. Cerrato R, Cunnington C, Crabtree MJ, et al. Endothelin-1 increases superoxide production in human coronary artery bypass grafts. Life Sci 2012;91(13-14):723-8. doi: S0024-3205(12)00147-6 [pii] 10.1016/j.lfs.2012.03.024 [published Online First: 2012/04/10]

15. Zeiher AM, Ihling C, Pistorius K, et al. Increased tissue endothelin immunoreactivity in atherosclerotic lesions associated with acute coronary syndromes. Lancet 1994;344(8934):1405-6. doi: S0140-6736(94)90571-1 [pii] [published Online First: 1994/11/19]

16. Böhm F, Ahlborg G, Pernow J. Endothelin-1 inhibits endothelium-dependent vasodilatation in the human forearm: reversal by ETA receptor blockade in patients with atherosclerosis. Clinical science 2002;102(3):321-7.

17. Loomis ED, Sullivan JC, Osmond DA, et al. Endothelin mediates superoxide production and vasoconstriction through activation of NADPH oxidase and uncoupled nitricoxide synthase in the rat aorta. J Pharmacol Exp Ther 2005;315(3):1058-64. doi: 10.1124/jpet.105.091728

18. Rosenkranz-Weiss P, Sessa WC, Milstien S, et al. Regulation of nitric oxide synthesis by proinflammatory cytokines in human umbilical vein endothelial cells. Elevations in tetrahydrobiopterin levels enhance endothelial nitric oxide synthase specific activity. $J$ Clin Invest 1994;93(5):2236-43. doi: 10.1172/JCI117221 [published Online First: 1994/05/01]

19. Barton M, d'Uscio LV, Shaw S, et al. ET(A) receptor blockade prevents increased tissue endothelin-1, vascular hypertrophy, and endothelial dysfunction in salt-sensitive hypertension. Hypertension 1998;31(1 Pt 2):499-504. [published Online First: 1998/02/07]

20. Zheng JS, Yang XQ, Lookingland KJ, et al. Gene transfer of human guanosine 5'triphosphate cyclohydrolase I restores vascular tetrahydrobiopterin level and endothelial function in low renin hypertension. Circulation 2003;108(10):1238-45. doi: 10.1161/01.CIR.0000089082.40285.C3

21. Romero M, Jimenez R, Sanchez M, et al. Quercetin inhibits vascular superoxide production induced by endothelin-1: Role of NADPH oxidase, uncoupled eNOS and PKC. Atherosclerosis 2009;202(1):58-67. doi: 10.1016/j.atherosclerosis.2008.03.007

22. Oesterle A, Laufs U, Liao JK. Pleiotropic Effects of Statins on the Cardiovascular System. Circ Res 2017;120(1):229-43. doi: 10.1161/CIRCRESAHA.116.308537 [published Online First: 2017/01/07]

23. Mayyas F, Baydoun D, Ibdah R, et al. Atorvastatin Reduces Plasma Inflammatory and Oxidant Biomarkers in Patients With Risk of Atherosclerotic Cardiovascular Disease. J Cardiovasc Pharmacol Ther 2018:1074248417753677. doi: 10.1177/1074248417753677 [published Online First: 2018/01/19]

24. Whitsett J, Martasek P, Zhao H, et al. Endothelial cell superoxide anion radical generation is not dependent on endothelial nitric oxide synthase-serine 1179 phosphorylation and endothelial nitric oxide synthase dimer/monomer distribution. Free Radic Biol Med 2006;40(11):2056-68. doi: 10.1016/j.freeradbiomed.2006.02.001 


\section{Acknowledgements}

We gratefully acknowledge the skilled help in harvesting vessels from the cardiothoracic surgeons Ravi Sayeed, Chandi Ratnatunga, Ravi Pillai and David Taggart at John Radcliffe Hospital, Oxford, UK. 